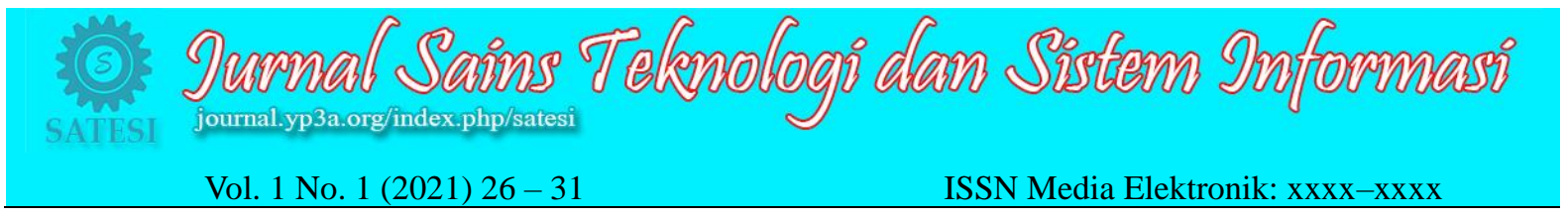

\title{
Implementasi Algoritma AES Pada QR-Code Sebagai Parameter Keaslian Data Dalam Pembuatan KTA
}

\author{
Nahar Mardiyantoro $^{1 *}$, Mefa Listiani $^{2}$ \\ ${ }^{1,2}$ Teknik Informatika, Fakultas Teknik dan Ilmu Komputer, Universitas Sains Al-Quran, Wonosobo, Indonesia \\ Email: ${ }^{1 *}$ mardziyant@fastikom-unsiq.ac.id, ${ }^{2}$ mefalistiani143@gmail.com
}

\begin{abstract}
The process of making KTA at UPT RPH Wonosobo Regency which is still carried out by typing prospective member data in MS Excel and editing it in the form of a card and then be printed, is considered ineffective so that it prolongs the process of making KTA. Besides that there is no guarantee of authenticity, so an application for making KTA is made with added the AES algorithm to speed up the performance of the KTA manufacturing process and guarantee its authenticity. The implementation of the AES Algorithm is included in the KTA checking URL which is converted into a QR-Code for easy scanning. This research is expected to help the process of making KTA at UPT RPH Wonosobo Regency and ensure the authenticity of the KTA made.
\end{abstract}

Keywords: AES Algorithm, QR-Code, KTA, Security, Authenticity.

\begin{abstract}
ABSTRAK
Proses pembuatan KTA pada UPT RPH kabupaten wonosobo yang masih dilakukan dengan mengetik data calon anggota pada MS Excel dan mengeditnya dalam bentuk kartu kemudian dicetak, proses tersebut dirasa kurang efektif sehingga memperlama proses pembuatan KTA. Selain itu juga tidak ada jaminan keasliannya, maka dibuatlah aplikasi pembuatan KTA dengan menambahkan algoritma AES untuk mempercepat kinerja proses pembuatan KTA dan menjamin keasliannya. Implementasi Algoritma AES dimasukkan ke dalam URL pengecekan KTA yang dikonversi menjadi QR-Code agar mudah dipindai dan mudah dilakukan pengecekan. Penelitian ini diharapkan dapat membantu proses pembuatan KTA di UPT RPH Kabupaten Wonosobo dan menjamin keaslian KTA yang dibuat.
\end{abstract}

Kata Kunci: Algoritma AES, QR-Code, KTA, Keamanan, Keaslian.

\section{Pendahuluan}

Rumah Potong Hewan atau yang disebut dengan RPH adalah suatu bangunan yang didesain dengan syarat tertentu digunakan sebagai tempat pemotongan hewan untuk konsumsi masyarakat umum. Berfungsi sebagai sarana untuk melaksanakan pemotongan hewan dengan benar, pemeriksaan hewan sebelum dan sesudah dipotong untuk menghasilkan daging yang aman, sehat, utuh dan halal.

Salah satu syarat diakuinya pekerja pemotong daging di UPT RPH Kabupaten Wonosobo adalah sudah memiliki Kartu Tanda Anggota (KTA). Proses pembuatan KTA yang lebih singkat dapat mempercepat calon anggota untuk segera bekerja dan meningkatkan kinerja UPT RPH Kabupaten Wonosobo.

Pemotongan hewan dilakukan oleh para pekerja pemotong daging yang terdiri dari 39 anggota, diantaranya yang bertugas sebagai penyembelih, pemotong kepala dan kaki, pengulitan, pemisah daging, dan pengeluaran jeroan.

Namun, saat ini pelaksanaan pemotongan hewan masih belum berjalan dengan tertib. Selain itu, proses pembuatan KTA dilakukan dengan cara mendesain KTA dahulu melalui Ms. Excel, kemudian diketik data diri anggotanya lalu mencetaknya. Hal ini akan menyebabkan data anggota pekerja pemotongan hewan tidak tersusun secara terkelompok karena pengetikannya tidak berurutan dan memperlama proses pembuatan KTA. Begitu juga dengan jaminan keaslian KTA tersebut. Dengan mudahnya membuat KTA secara manual, KTA menjadi rawan dengan praktik pemalsuan. Agar pemotongan bisa tertib, cepat, efisien dan aman dibutuhkan suatu aplikasi yang dapat mengolah data secara sistematis dan meng-enkripsi KTA dengan aman.

Diterima Redaksi: 09-09-2021 | Selesai Revisi: 09-09-2021 | Diterbitkan Online: 10-09-2021 
Beberapa metode yang dapat digunakan untuk meng- yang dapat diterapkan seperti desain KTA dan biodata enkripsi informasi yang dimuat dalam KTA antara lain para pekerja

Algoritma IDEA, DES, Blowfish, dan AES. Namun, berdasarkan pengujian yang telah dilakukan dari segi 2.4 Metode Pengembangan Sistem

kecepatan dan ukuran file yang dihasilkan, Algoritma Pembuatan aplikasi ini menggunakan metode waterfall. AES merupakan algoritma yang terbaik di antara ketiga Tahapan yang dilakukan pada metode tersebut dapat algoritma tersebut [1].

Cara kerja Algoritma AES menggunakan substitusi dan permutasi dalam orientasi byte yang diulang-ulang sehingga hasil enkripsi lebih aman. Algoritma ini mempunya kunci internal yang berbeda-beda di setiap putarannya [2].

Hasil dari Algoritma AES tidak bisa langsung dicantumkan ke dalam KTA karena akan mempersulit seseorang yang akan mengecek keaslian KTA tersebut. Sehingga Algoritma yang dihasilkan di-enkripsi lagi ke dalam sebuah Quick Response Code (QR-Code). $Q R$ Code merupakan pengembangan dari Barcode yang mampu menyimpan informasi agar bisa diolah dengan cepat dan tepat. Dengan di-enkripsi-kan ke dalam $Q R$ -

Code, hasil enkripsi bisa diidentifikasi oleh semua orang menggunakan aplikasi pembaca $Q R$-Code yang sudah umum digunakan pada Smartphone masingmasing [3].

Berdasarkan beberapa hal di atas, penulis berkeinginan untuk merancang suatu aplikasi atau program yang tepat dengan membuat suatu aplikasi yang dapat membantu instansi. Hal ini tentunya akan sangat membantu dalam kelancaran atau kecepatan penyelesaian berbagai pekerjaan apapun. Dengan adanya aplikasi ini instansi dapat lebih maju dan semua data yang diperlukan bisa didapat dengan cepat dan mudah.

\section{Metode Penelitian}

\subsection{Objek Penelitian}

Objek penelitian dalam penelitian ini adalah Pembuatan KTA di UPT RPH Kabupaten Wonosobo.

\subsection{Jenis Penelitian}

Jenis Penelitian ini merupakan penelitian tersebut akan ditransformasikan ke dalam 10 kunci pengembangan yaitu penelitian yang bertujuan untuk mengembangkan atau menghasilkan suatu produk [4]. Dalam penelitian ini produk yang dihasilkan adalah sebuah aplikasi untuk mempercepat proses pembuatan KTA di UPT RPH Kabupaten Wonosobo.

\subsection{Data Penelitian}

Data dalam penelitian ini bersumber dari dua jenis data, yaitu data primer dan data sekunder. Data primer yang didapat melalui proses wawancara adalah data mengenai alur pembuatan KTA siapa saja yang berwenang untuk membuat KTA. Sedangkan data sekunder dalam penelitian ini adalah data penunjang yang dikumpulkan berasal dari dokumen-dokumen yang berkaitan dengan KTA dan sistem pengamanan dilihat pada gambar di bawah ini :

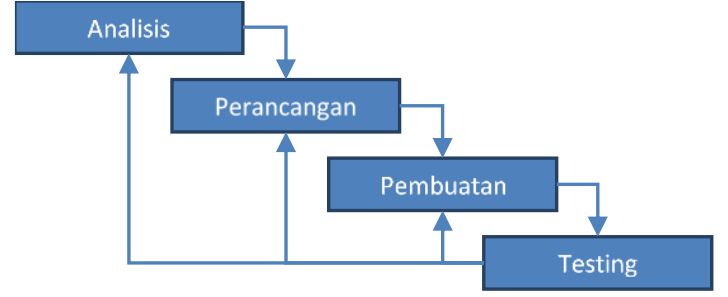

Gambar 1. Metode Waterfall

\subsection{Penerapan Algoritma AES}

Penerapan Algoritma AES Pada Aplikasi Pembuatan KTA ada pada enkripsi dari kode anggota yang tersimpan di dalam Data base digabungkan dengan URL yang nantinya akan mengarahkan ke dalam halaman pengecekan KTA. URL yang sudah berisi enkripsi kode anggota kemudian dikonversi menjadi bentuk $Q R$-Code. $Q R$-Code ini disisipkan ke dalam KTA agar lebih mudah dalam melakukan pengecekan KTA.

\section{Hasil dan Pembahasan}

\subsection{Proses enkripsi Algoritma AES}

Untuk penjelasan proses enkripsi Algoritma AES kita ambil contoh pada salah satu kode anggota ditambahkan nama anggota itu sendiri, yaitu "001_Ribudi".

Algoritma AES merupakan algoritma yang menggunakan transformasi substitusi dan permutasi yang diulang-ulang menggunakan kunci pada tiap pengulangannya [5]. Kunci pada proses putaran pertama dapat kita tentukan sendiri. Selanjutnya kunci yang berbeda melalui proses Key Schedule. Dalam hal ini kunci yang kita tentukan adalah "abcdefghijuklmno".

Sebelum masuk ke tahap enkripsi, ubah terlebih dahulu teks yang akan dienkripsi dan kunci yang telah ditentukan ke dalam bentuk Hex yang kemudian disebut sebagai Plaintext dan Chiper Key. Sehingga dihasilkan :

\begin{tabular}{ll}
\multicolumn{2}{c}{ Tabel 1. Perubahan pada bentuk Hex } \\
\hline Teks/Key & Hex \\
\hline 001_Ribudi & 3030315F526962756469000000000000 \\
abcdefghijuklmno & 6162636465666768696A756B6C6D6E6F \\
\hline
\end{tabular}

Proses pertama dalam meng-enkripsi menggunakan Algoritma AES adalah Initial Round yaitu pengkalian XOR antara plaintext dengan chiper key. Kemudian

DOI: $\mathrm{xxxx}$

Lisensi: Creative Commons Attribution 4.0 International (CC BY 4.0) 
hasil pengkalian tersebut disubsitusikan dengan tabel S- Proses pertama pada Dekripsi AES adalah Box. Proses ini dinamakan SubBytes. Setelah itu AddRoundKey, yaitu perkalian XOR antara Chiper Text lakukan proses ShiftRows, yaitu pergeseran ke kiri dengan Round Key ke 10. Kemudian InvShiftRows masing-masing baris pada hasil SubBytes sejauh $\mathrm{n}$ yaitu pergeseran ke kanan masing-masing baris pada kolom sesuai dengan letak barisnya. Proses selanjutnya hasil AddRoundKey. Setelah itu konversi hasil yaitu MixColumns. Pada proses ini dilakukan perkalian InvShiftRows dengan Tabel Invers S-Box. Proses ini hasil sebelumnya dengan sebuah matrik. Kemudian dinamakan InvSubBytes. Langkah berikutnya yaitu lanjut ke proses AddRoundKey, yaitu perkalian XOR melakukan AddRoundKey putaran ke 2, dilanjutkan antara hasil MixColumns dengan RoundKey (hasil Key dengan InvMixColumns, yaitu perkalian hasil Schedule) pertama. AddRoundKey dengan matrik khusus, kemudian Keempat proses tersebut kemudian diulang sampai 9 lakukan proses InvShiftRows putaran ke 2 lalu proses kali. Dan di perulangan yang ke 10 lakukan proses InvSubBytes putaran ke 2. Keempat Langkah ini yang sama kecuali proses MixColumns. Ilustrasi proses diulang sampai dengan 9 kali. Langkah terakhir pada enkripsi Algoritma AES dapat dilihat pada gambar di proses dekripsi yaitu AddRoundKey yang merupakan bawah ini :

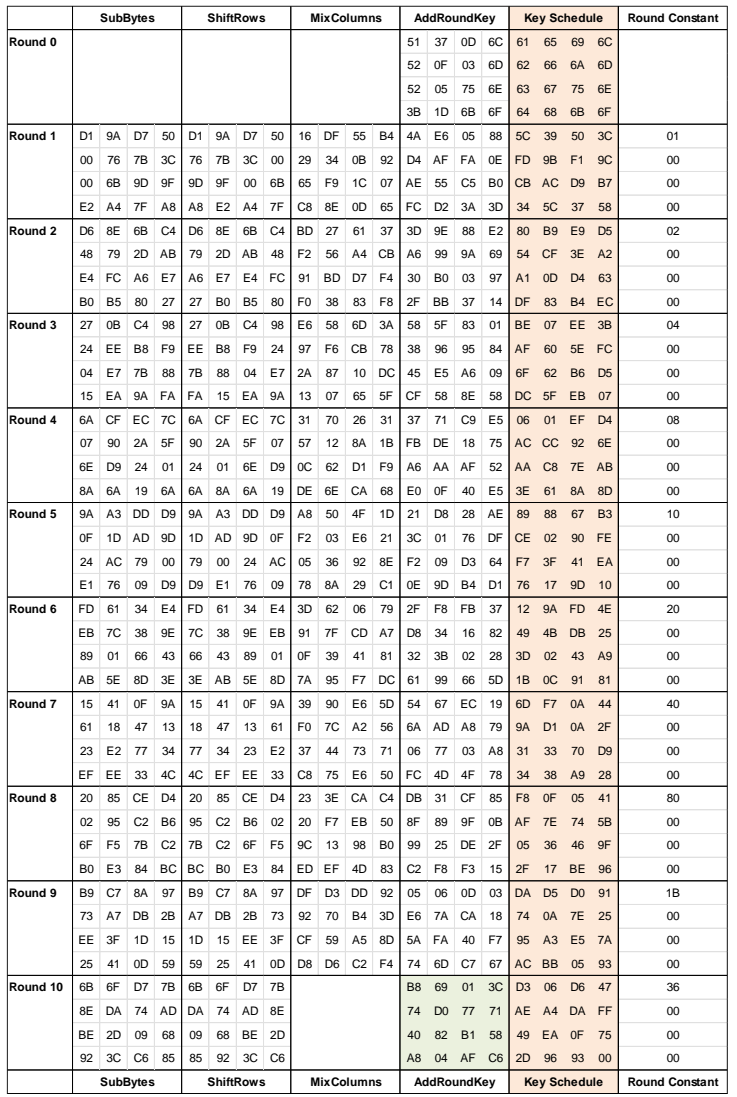

Gambar 2. Enkripsi Algoritma AES adalah :

Hasil keluaran (output) dari proses enkripsi di atas B87440A869D082040177B1AF3C7158C6

Yang selanjutnya disebut dengan Chiper Text.

\subsection{Proses Dekripsi Algoritma AES}

Pada proses dekripsi, langkah yang dilakukan sama seperti dengan enkripsi, hanya saja prosesnya dibalik. RoundKey yang digunakan juga dibalik urutannya untuk masing-masing putaran, mulai dari RoundKey ke 10 untuk putaran pertama, kemudian mundur sampai ke Chiper Key [6]. perkalian XOR antara hasil sebelumnya dengan Chiper Key yang telah dibuat sebelumnya.

Berikut adalah Ilustrasi proses dekripsi Algoritma AES untuk setiap langkahnya :

\begin{tabular}{|c|c|c|c|c|c|c|c|c|c|c|c|c|c|c|c|c|}
\hline \multicolumn{4}{|c|}{ SubBytes } & \multicolumn{4}{|c|}{ ShittRows } & \multicolumn{3}{|c|}{ MixColumns } & \multicolumn{3}{|c|}{\begin{tabular}{|l|} 
AddRoundKey \\
\end{tabular}} & \begin{tabular}{|l} 
Key Schedule \\
\end{tabular} & \multirow[t]{2}{*}{ Round Constant } & \multirow[b]{2}{*}{ Round 10} \\
\hline & & & & & & & & & & & $\begin{array}{ll}30 & 55 \\
30 & 65 \\
31 & 6 \\
5 & 6 \\
5 & 75 \\
\end{array}$ & $\begin{array}{ll}62 & 64 \\
69 & 69 \\
62 & 00 \\
75 & 00 \\
\end{array}$ & $\begin{array}{l}00 \\
00 \\
00 \\
00\end{array}$ & $\begin{array}{llll}61 & 65 & 69 & 6 \mathrm{C} \\
62 & 66 & 6 \mathrm{~A} & 6 \mathrm{D} \\
63 & 67 & 75 & 6 \mathrm{E} \\
64 & 68 & 6 \mathrm{~B} & 6 \mathrm{~F} \\
\end{array}$ & & \\
\hline 51 & 37 & $O D$ & & D1 & $9 A$ & D7 5 & & D1 $9 \mathrm{~A}$ & D7 & & $16 \mathrm{DF}$ & DF 55 & B4 & $\begin{array}{llll}5 \mathrm{C} & 39 & 50 & 3 \mathrm{C}\end{array}$ & 01 & Round 9 \\
\hline 52 & OF & 03 & & 00 & 767 & $\begin{array}{ll}78 \quad 3 \\
78\end{array}$ & & 7678 & 30 & 00 & 2934 & $\begin{array}{lll}34 & 0 B\end{array}$ & 92 & $\begin{array}{llll}F D & 9 B & F 1 & 9 C\end{array}$ & 00 & \\
\hline 52 & 05 & 75 & & 00 & $6 \mathrm{~B}$ & 9D 9 & & $9 D \quad 9 F$ & 00 & & $65 \mathrm{Fs}$ & $=9 \quad 1 \mathrm{C}$ & 07 & $\begin{array}{llll}C B & A C & D 9 & B 7\end{array}$ & 00 & \\
\hline 3в & $1 \mathrm{D}$ & $6 \mathrm{~B}$ & $6 \mathrm{~F}$ & E2 & A4 & $7 \mathrm{~F} \mathrm{~A}$ & A8 & A8 E2 & A4 & $7 \mathrm{~F}$ & $\begin{array}{lll}C 8 & 8 E \\
\end{array}$ & $\begin{array}{lll}3 E & 0 D \\
\end{array}$ & 65 & $\begin{array}{llll}34 & 5 \mathrm{C} & 37 & 58\end{array}$ & 00 & \\
\hline 4A & E6 & 05 & 88 & D6 & $8 \mathrm{E}$ & $6 \mathrm{~B}$ & 445 & $\begin{array}{ll}D 6 & 8 E \\
\end{array}$ & $6 \mathrm{~B}$ & $\mathrm{C}^{\mathrm{C}}$ & BD 2 - & 2761 & 37 & $\begin{array}{llll}80 & \text { B9 } & \text { E9 } & \text { D5 }\end{array}$ & 02 & Round 8 \\
\hline D4 & AF & FA & $O E$ & 48 & 79 & $2 \mathrm{DA}$ & $\mathrm{AB}$ & $792 \mathrm{D}$ & AB & 48 & F2 $5 \mathrm{C}$ & $\begin{array}{lll}56 & \mathrm{~A} 4\end{array}$ & св & 54 CF $3 E$ A2 & 00 & \\
\hline $\mathrm{AE}$ & 55 & C5 & Bo & E4 & $\mathrm{FC}$ & A6 $E$ & E7 & A6 E7 & E4 F & $\mathrm{FC}$ & $91 \mathrm{BL}, \mathrm{C}$ & $\begin{array}{lll}3 D & D 7\end{array}$ & F4 & $\begin{array}{llll}A & 0 D & D 4 & 63\end{array}$ & 00 & \\
\hline $\mathrm{FC}$ & D2 & $3 A$ & 30 & Bo & B5 & 802 & 27 & 27 Bo & B5 & 80 & Fo $\quad 36$ & $38 \quad 83$ & $F_{8}$ & $\begin{array}{lllll}\text { DF } & 83 & \text { B4 } & \text { EC }\end{array}$ & 00 & \\
\hline 3D & $9 \mathrm{E}$ & 88 & E2 2 & 27 & $\mathrm{OB}$ & C4 9 & 98 & $27 \quad 0 B$ & C4 & 98 & $\begin{array}{lll}E 6 & 58 \\
\end{array}$ & $686 \mathrm{D}$ & $3 \mathrm{~A}$ & BE 07 EE 38 & 04 & \begin{tabular}{|l|} 
Round 7 \\
\end{tabular} \\
\hline A6 & 99 & $9 A$ & 69 & 24 & EE & $B 8 \mathrm{~F}$ & F9 E E & EE $\mathrm{B} 8$ & F9 & 24 & $97 \mathrm{Fe}$ & $=6 \quad \mathrm{CB}$ & 78 & AF $60 \quad 5 E \quad F C$ & 00 & \\
\hline 30 & Bo & 03 & & 04 & E7 & $\begin{array}{ll}78 & 8 \\
7\end{array}$ & & $\begin{array}{ll}78 & 88 \\
\end{array}$ & 04 & E7 & $2 \mathrm{CA}$ & $87 \quad 10$ & $\mathrm{DC}$ & $6 \mathrm{~F} \quad 62 \quad \mathrm{~B} 6 \quad \mathrm{D} 5$ & 00 & \\
\hline $2 F$ & BB & 37 & ${ }^{14}$ & 15 & EA & $9 \mathrm{~A} F$ & $F A[F$ & FA 15 & EA $\mathrm{S}$ & 9A & $\begin{array}{lll}13 & 07 \\
\end{array}$ & $\begin{array}{lll}07 & 65 \\
\end{array}$ & $5 \mathrm{~F}$ & $\begin{array}{llll}\text { DC } & 5 F & E B & 07\end{array}$ & 00 & \\
\hline 58 & $5 F$ & 83 & 01 & $6 \mathrm{~A}$ & CF & EC 7 & 7c 6 & $6 \mathrm{~A}$ CF & EC & $7 \mathrm{C}$ & 317 & $\begin{array}{ll}70 & 26\end{array}$ & 31 & $\begin{array}{llll}06 & 01 & E F & D 4\end{array}$ & 08 & Round 6 \\
\hline 38 & 96 & 95 & 84 & 07 & 90 & $2 A 5$ & $5 F$ & $90 \quad 2 \mathrm{~A}$ & $5 F$ & 07 & 5712 & $128 \mathrm{~A}$ & $1 \mathrm{~B}$ & $A C \quad C C \quad 92 \quad 6 E$ & 00 & \\
\hline & E5 & $A_{6}$ & 09 & $6 \mathrm{E}$ & D9 & 240 & 012 & 2401 & $6 \mathrm{E}$ & D9 & oc 62 & 62 D1 & F9 & $\begin{array}{llll}A A & C 8 & 7 E & A B\end{array}$ & 00 & \\
\hline CF & 58 & $8 \mathrm{E}$ & 58 & $8 \mathrm{~A}$ & $6 \mathrm{~A}$ & 196 & $6 \mathrm{~A}$ & $6 \mathrm{~A} \quad 8 \mathrm{~A}$ & $6 \mathrm{~A}$ & 19 & DE 65 & SE CA & 68 & $\begin{array}{llll}3 E & 61 & 8 A & 80\end{array}$ & 00 & \\
\hline 37 & 71 & c9 & E5 & $9 \mathrm{~A}$ & A3 & DD D & $\mathrm{Dg}=\mathrm{s}$ & $\begin{array}{ll}9 \mathrm{~A} & \mathrm{~A} 3 \\
\end{array}$ & DD & D9 & A8 55 & $\begin{array}{lll}50 & 4 F\end{array}$ & 10 & \begin{tabular}{|llll}
89 & 88 & 67 & B3
\end{tabular} & 10 & Round 5 \\
\hline $\mathrm{FB}$ & DE & 18 & 75 & OF & $10 \mathrm{~A}$ & AD 9 & 90 & 1D AD & $9 \mathrm{D}$ & OF & F2 03 & 03 E6 & 21 & CE $02 \quad 90 \mathrm{FE}$ & 00 & \\
\hline A6 & $A A$ & AF & 52 & 24 & $A C$ & 79 & 00 & 7900 & $24 \mathrm{~A}$ & $\mathrm{AC}$ & 0536 & $\begin{array}{ll}36 & 92\end{array}$ & $8 \mathrm{E}$ & F7 $3 F \quad 41 \quad E A$ & 00 & \\
\hline E0 & OF & 40 & E5 & E1 & 76 & 09 & D9 & $\begin{array}{ll}\text { D9 E1 } \\
\end{array}$ & 76 & 09 & 788 & 3A 29 & C1 & $\begin{array}{llll}76 & 17 & 9 D & 10\end{array}$ & 00 & \\
\hline 21 & D8 & 28 & $\mathrm{AE}$ & FD & 61 & 34 & E4 & FD 61 & 34 & E4 & $\begin{array}{ll}30 & 62 \\
\end{array}$ & 6206 & 79 & 12 9A $\quad$ FD $\quad 4 E$ & 20 & Round 4 \\
\hline $3 \mathrm{C}$ & 01 & 76 & DF & EB & $7 \mathrm{C}$ & $38 \mathrm{~s}$ & $\mathrm{GE}[$ & 7038 & $9 \mathrm{E}$ & $\mathrm{EB}$ & 917 & $\mathrm{FF} C \mathrm{CD}$ & A7 & 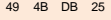 & 0 & \\
\hline $\mathrm{F} 2$ & 09 & D3 & 64 & 89 & 01 & 66 & 43 & $\begin{array}{ll}66 & 43 \\
\end{array}$ & 89 & 01 & of $3 \mathrm{~s}$ & 3941 & 81 & $\begin{array}{llll}3 D & 02 & 43 & A 9\end{array}$ & 00 & \\
\hline OE & $9 \mathrm{DE}$ & B4 & D1 & AB & $5 E$ & $8 \mathrm{D}$ & 3E & उE $A B$ & $5 E$ & $8 \mathrm{D}$ & $\begin{array}{ll}7 \mathrm{~A} & 9 \mathrm{~S} \\
\mathrm{C}\end{array}$ & $\begin{array}{ll}95 & F 7 \\
\end{array}$ & $\mathrm{DC}$ & $\begin{array}{llll}1 \mathrm{~B} & 0 \mathrm{C} & 91 & 81\end{array}$ & 00 & \\
\hline $2 F$ & $F 8 \mathrm{~F}$ & $F B$ & 37 & 15 & 41 & OF $\mathrm{E}$ & $9 A$ & 1541 & OF $\mathrm{g}, \mathrm{S}$ & $9 A$ & $39 \mathrm{9}$ 9 & 90 E6 & $5 \mathrm{D}$ & $\begin{array}{llll}6 D & F 7 & 0 A & 44\end{array}$ & 40 & Round 3 \\
\hline D8 & 34 & 16 & 82 & 61 & 18 & 47 & 13 & 1847 & 13 & 61 & Fo 76 & CC A2 & 56 & $9 A \quad D 1 \quad 0 A \quad 2 F$ & 00 & \\
\hline 32 & зв & 02 & 28 & 23 & E2 & 77 & 34 & $77 \quad 34$ & 23 & E2 & $37 \quad 4 . \quad 5$ & 4473 & 71 & $\begin{array}{llll}31 & 33 & 70 & D 9\end{array}$ & 00 & \\
\hline 61 & 99 & $66=$ & $5 \mathrm{D}$ & EF & EE & 33 & 4C & $4 C \mathrm{EF}$ & $\mathrm{EE}$ & 33 & C8 75 & $75 \quad$ E6 & 50 & $\begin{array}{llll}34 & 38 & \text { A9 } & 28\end{array}$ & 00 & \\
\hline 54 & 67 & EC & 19 & 20 & 85 & CE & D4 & 2085 & CE & D4 & $23 \quad 36$ & $3 E C A$ & C4 & $\begin{array}{llll}\text { F8 } & \text { OF } & 05 & 41\end{array}$ & 80 & Round 2 \\
\hline $6 \mathrm{~A}$ & $A D$ & A8 & 79 & 02 & 95 & C2 & B6 & $95 \mathrm{C} 2$ & B6 & 02 & $20 \mathrm{~F}$ & $=7 \mathrm{~EB}$ & 50 & $\begin{array}{llll}A F & 7 E & 74 & 5 B\end{array}$ & 00 & \\
\hline 06 & 77 & 03 & A8 & $6 \mathrm{~F}$ & F5 & 78 & C2 & $\begin{array}{ll}7 \mathrm{~B} & \mathrm{C} 2 \\
\end{array}$ & $6 \mathrm{~F}$ & F5 & 901 & 1398 & Bo & $\begin{array}{llll}05 & 36 & 46 & 9 \mathrm{~F}\end{array}$ & 00 & \\
\hline $\mathrm{FC}$ & $4 \mathrm{D}$ & $4 \mathrm{~F}$ & 78 & во & E3 & 84 & $B C$ & BC BO & E3 & 84 & ED EF & EF $4 D$ & 83 & $\begin{array}{llll}2 \mathrm{~F} & 17 & \mathrm{BE} & 96 \\
\end{array}$ & 00 & \\
\hline DB & $31 \mathrm{c}$ & CF & 85 & B9 & $\mathrm{C7}$ & $8 \mathrm{~A}$ & $97 \mid$ & B9 $\mathrm{C7}$ & $8 \mathrm{~A}$ & ${ }^{97}$ & DF D & D3 50 & 92 & $\begin{array}{llll}\text { DA } & \text { D5 } & \text { D0 } & 91\end{array}$ & 18 & Round 1 \\
\hline $8 \mathrm{~F}$ & 89 & $9 \mathrm{~F}$ & $\mathrm{OB}$ & 73 & A7 & DB & $2 \mathrm{~B}$ & A7 DB & $2 B$ & 73 & 927 & $\begin{array}{ll}70 & \mathrm{~B} 4\end{array}$ & $3 \mathrm{D}$ & $\begin{array}{llll}74 & \text { OA } & 7 E & 25\end{array}$ & 00 & \\
\hline 99 & 25 & $\mathrm{DE}$ & $2 \mathrm{~F}$ & EE & $3 F$ & 1D & 15 & 1D 15 & EE 3 & $3 \mathrm{~F}$ & CF $5 \mathrm{~S}$ & 59 A5 & $8 D$ & $\begin{array}{llll}95 & \text { A3 } & \text { E5 } & 7 \mathrm{~A}\end{array}$ & 00 & \\
\hline C2 & $F 8$ & F3 & 15 & 25 & 41 & OD & 59 & $\begin{array}{ll}5925 \\
\end{array}$ & & $O D$ & $\begin{array}{lll}D 8 & D \\
\end{array}$ & $66 \quad \mathrm{C} 2$ & $\mathrm{~F}_{4}$ & $\begin{array}{llll}\text { AC } & \text { BB } & 05 & 93\end{array}$ & 00 & \\
\hline 05 & 06 & $O D$ & & $6 \mathrm{~B}$ & $6 \mathrm{~F}$ & D7 & & & & & $6 B \quad 6 F$ & $\begin{array}{ll}6 F & D 7\end{array}$ & 78 & \begin{tabular}{|llll} 
D3 & 06 & D6 & 47
\end{tabular} & 36 & Round 0 \\
\hline E6 & $7 \mathrm{AC} C \mathrm{C}$ & CA & 18 & $8 \mathrm{E}$ & $D A$ & 74 & $\mathrm{AD}$ & & & & DA 74 & 74 AD & $8 \mathrm{E}$ & AE A4 DA FF & 00 & \\
\hline $5 \mathrm{~A}$ & FA & 40 & $F 7$ & BE & $2 \mathrm{D}$ & 09 & 68 & & & & $09 \quad 68$ & 68 BE & $2 \mathrm{D}$ & 49 EA OF 75 & 0 & \\
\hline & $6 \mathrm{D}$ & C7 & & 92 & $3 \mathrm{C}$ & C6 & & & & & $\begin{array}{ll}85 & 92 \\
\end{array}$ & $923 \mathrm{C}$ & C6 & $\begin{array}{llll}2 D & 96 & 93 & 00\end{array}$ & 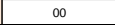 & \\
\hline & SubBy & Bytes & & & Shi & & & Mix & olumns & & & undke & & Key Schedule & sund Con & \\
\hline
\end{tabular}

Gambar 3. Dekripsi Algoritma AES

Berdasarkan proses dekripsi di atas, Output yang dihasilkan adalah :

\section{$3030315 F 526962756469000000000000$}

Hasil ini masih berupa Plaintext yang berbentuk Hex. Apabila diubah ke dalam teks maka akan menghasilkan

$$
\text { "001_Ribudi" }
$$

3.3. Implementasi Algoritma AES pada Aplikasi Pembuatan KTA

DOI: $\mathrm{xxxx}$

Lisensi: Creative Commons Attribution 4.0 International (CC BY 4.0) 
Penerapan Algoritma AES pada aplikasi pembuatan

KTA ada pada $Q R$-Code yang berisi URL halaman 3.4. Implementasi User Interface Aplikasi pengecekan KTA yang sudah digabung dengan hasil Sebelum mengakses Sistem Informasi Pembuatan KTA enkripsi kode anggota menggunakan Algoritma AES. UPT RPH Kabupaten Wonosobo, pengguna / admin URL halaman pada pembahasan ini adalah : http://ktarph.rf.gd/kta_detail.php?id= b87440a869d082040177b1af3c7158c6 diwajibkan melakukan login terlebih dahulu untuk memastikan bahwa pengguna / admin tersebut benarbenar merupakan petugas resmi dari UPT RPH Kabupaten Wonosobo.

Berikut ini adalah contoh KTA yang sudah disispkan $Q R$-Code yang berisi URL dan enkripsi Algoritma AES

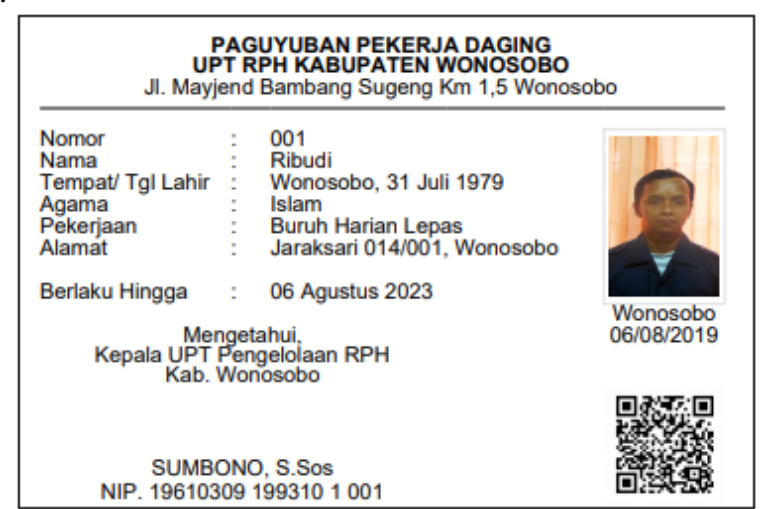

Gambar 4. Contoh KTA

Untuk pengecekan KTA dilakukan dengan memasuki halaman pengecekan KTA yang didapat dari hasil pemindaian $Q R$-Code. Berikut adalah tampilan pemindaian $Q R$-Code dan halaman pengecekan KTA :
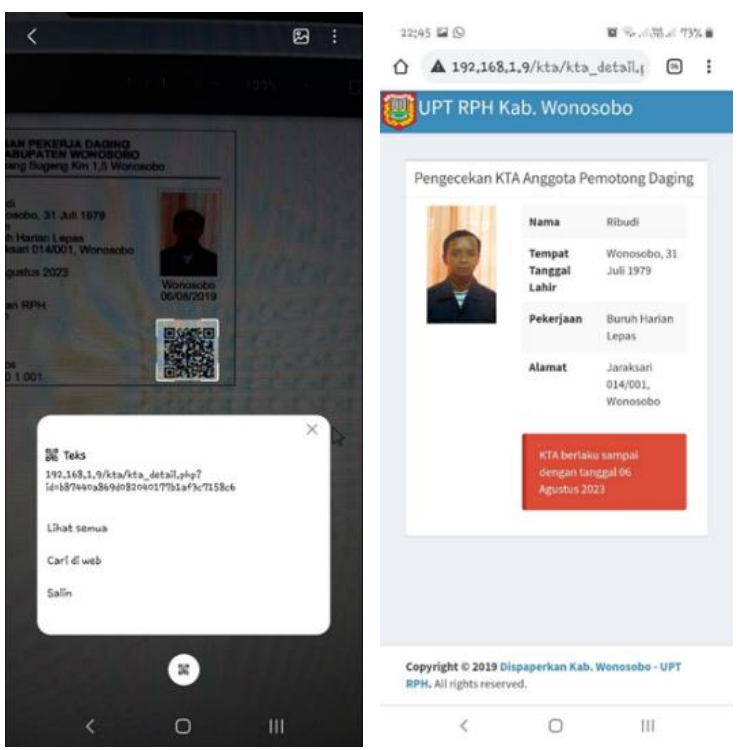

Gambar 5. Tampilan proses pengecekan KTA

Berdasarkan hasil pada halaman pengecekan dapat disimpulkan bahwa data yang tertera pada halaman pengecekan sama dengan data yang tertera pada KTA aslinya.

Selain itu bisa juga ditambahkan beberapa fitur baru seperti pendaftaran secara online atau bahkan pembayaran biaya pendaftaran secara online.

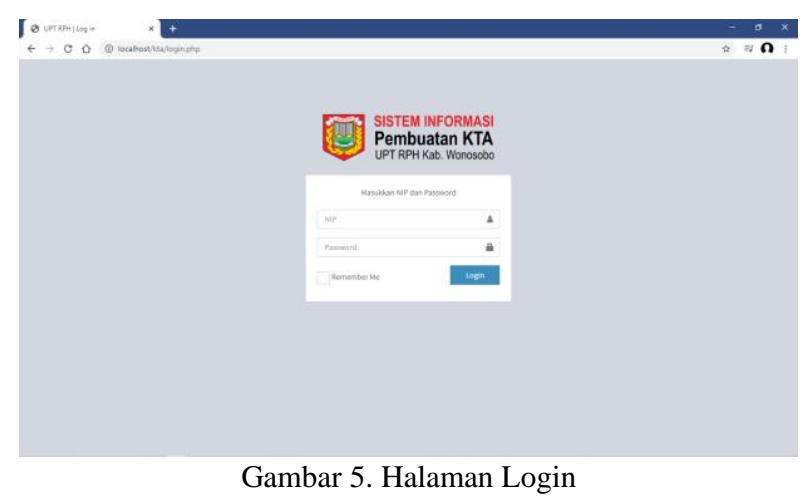

Halaman utama sistem informasi ini menampilkan informasi mengenai jumlah anggota yang sudah ada maupun anggota yang baru ditambahkan. Untuk menambahkan anggota baru juga bisa langsung dilakukan pada halaman ini, termasuk mencetak KTAnya.

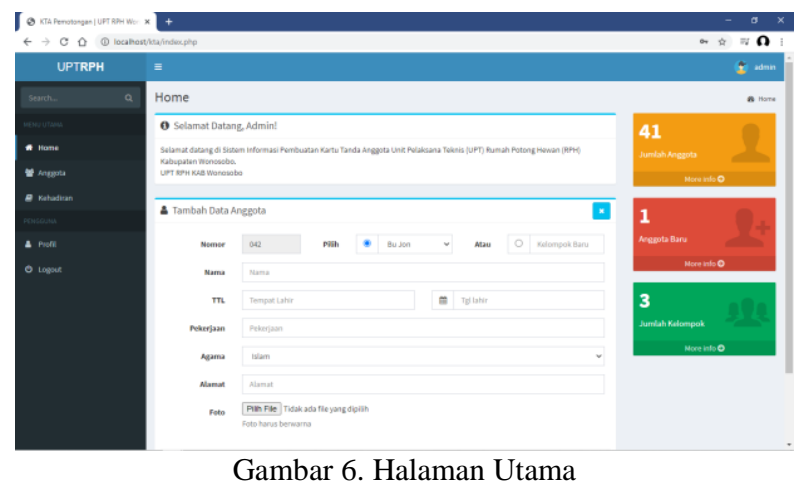

Halaman Anggota menampilkan data anggota secara keseluruhan mapupun kelompok. Di sini juga terdapat tombol untuk menambahkan data anggota, edit data anggota, hapus anggota, dan cetak KTA. Dari halaman ini pula terdapat tombol untuk mencetak data anggota.

DOI: $\mathrm{xxxx}$

Lisensi: Creative Commons Attribution 4.0 International (CC BY 4.0) 


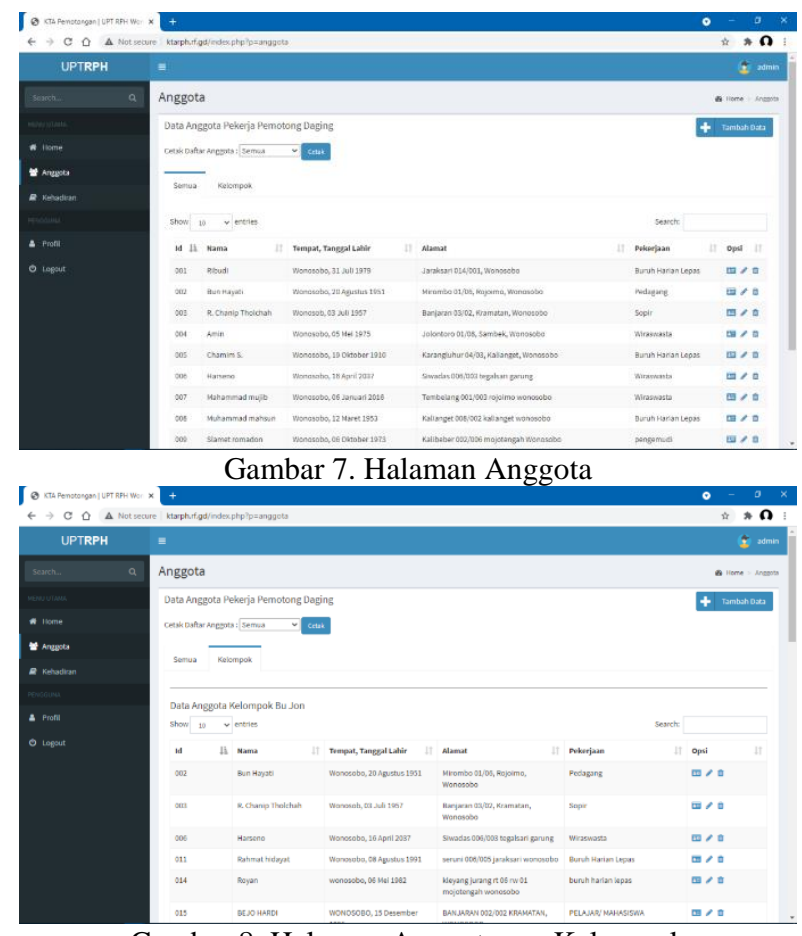

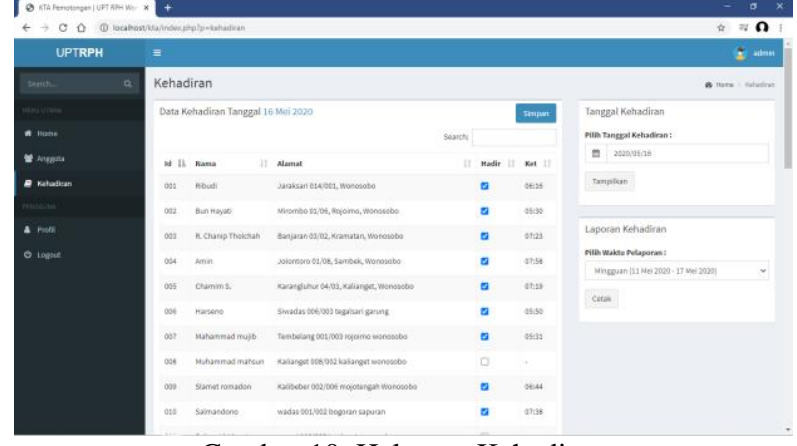

Gambar 10. Halaman Kehadiran

Halaman Cetak Kehadiran menampilkan pratinjau laporan kehadiran bulanan maupun mingguan yang akan dicetak. Untuk memudahkan penyampaian informasi, tiap kolom kehadiran terdapat warna tertentu untuk membedakan status kehadiran anggota. Warna hijau mewakili kehadiran, sedangkan warna merah mewakili ketidakhadiran. Halaman ini berformat .pdf, sehingga bisa langsung dicetak ataupun diunduh ke komputer.

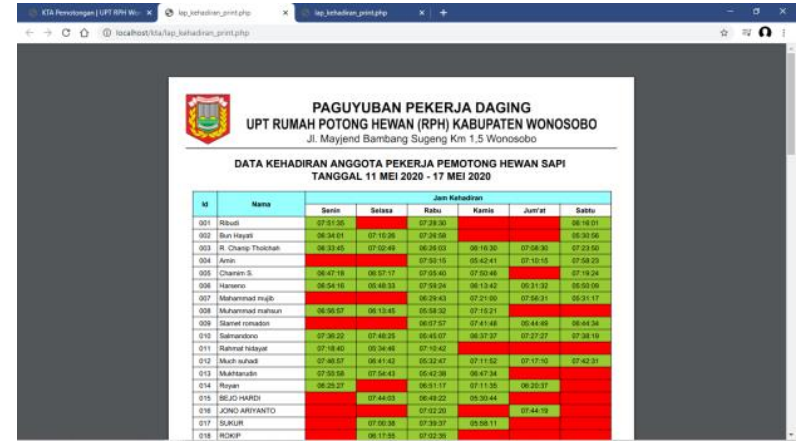

Gambar 11. Halaman Cetak Kehadiran Mingguan

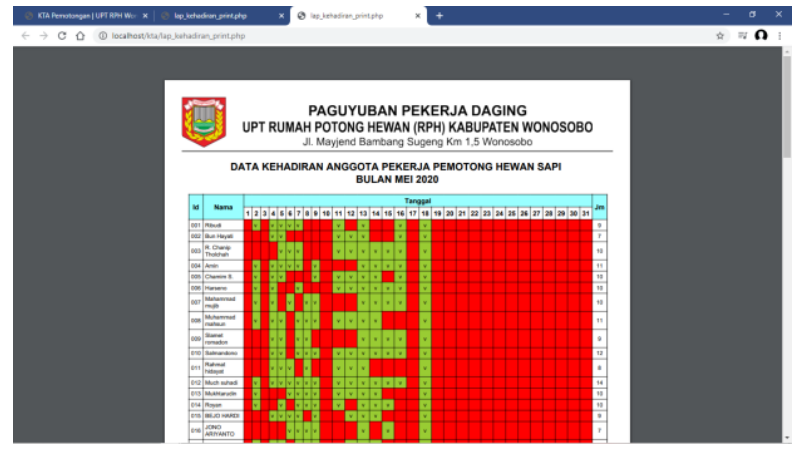

Gambar 12. Halaman Cetak Kehadiran Bulanan

Halaman ini menampilkan form edit untuk mengubah profil pengguna / admin

DOI: $\mathrm{xxxx}$

Lisensi: Creative Commons Attribution 4.0 International (CC BY 4.0) 


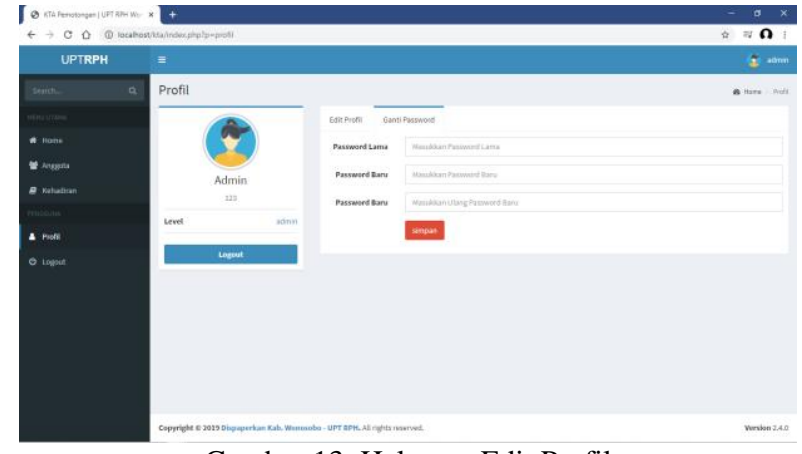

Gambar 13. Halaman Edit Profil

Pengujian sistem berguna untuk memastikan bahwa sistem dapat berjalan sesuai dengan harapan. Pengujian yang dipakai pada penelitian ini adalah Pengujian Black Box.

Pengujian Black Box merupakan pengujian yang mengutamakan kesesuaian program. Pengujian ini tidak memerlukan pengetahuan mengenai struktur internal pada program [7]. Dengan begitu semua orang dapat melakukan pengujian ini.

Pengujian untuk penerapan Algoritma AES pada $Q R$ Code dalam penelitian ini dapat dilihat pada tabel di berikut :

\subsection{Pengujian Sistem}

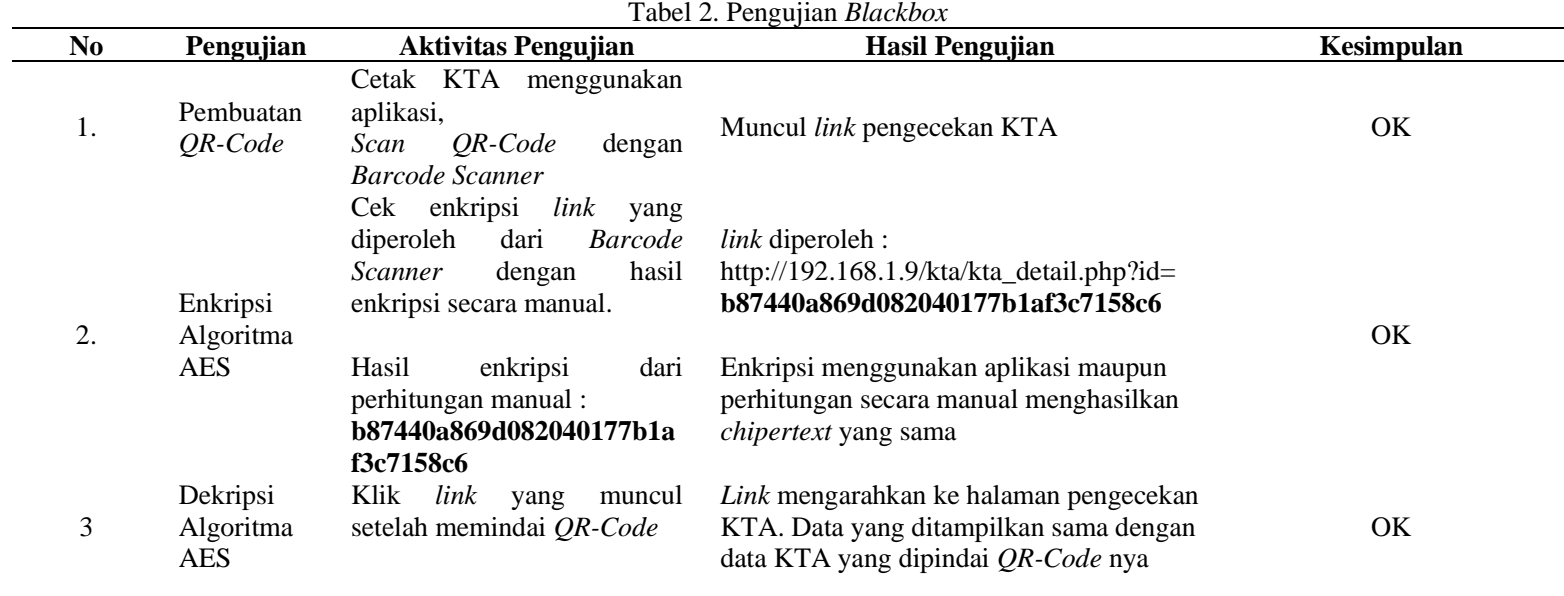

\section{Kesimpulan}

Setelah dilakukan penelitian, dapat disimpulkan bahwa Algoritma AES sanggup mengenkripsi dan menjamin informasi yang ada di dalam KTA dengan baik karena aplikasi yang dibuat bisa berjalan sesuai dengan hasil yang diharapkan. Hal ini dapat dibuktikan dengan sama persisnya data yang tertera pada halaman pengecekan KTA dengan KTA asli. Sehingga proses pembuatan KTA dapat dilakukan dengan mudah dan cepat serta

\section{Referensi}

[1] Raharjo, Tri. "Aplikasi Pengamanan Pesan Teks Menggunakan RC6 dan AES Berbasis Android". Diss. Universitas Mercu Buana Yogyakarta, 2018.

[2] Musabbihah, Diana. "Perencanaan Sistem Keamanan pada Jaringan Komunikasi ITS (Intelligent Transport System) Antara OBU dan TMC Server". Diss. Institut Teknologi Sepuluh
Nopember, 2018.

[3] Baihaqy, Muhammad Alif Muwafiq, Muhamad Fuat Asnawi, and Siti Fatimah. "Rancang Bangun Mobile Verifikator Hewan Layak Qurban Menggunakan Qr Code Berbasis Library Zxing." Jurnal Penelitian dan Pengabdian Kepada Masyarakat UNSIQ 7.2 pp. 194-201, 2020.

[4] Muyaroah, Siti, and Mega Fajartia. "Pengembangan Media Pembelajaran Berbasis Android dengan menggunakan Aplikasi Adobe Flash CS 6 pada Mata Pelajaran Biologi." Innovative Journal of Curriculum and Educational Technology 6.2, pp. 2226, 2017.

[5] Permana, Angga Aditya, and Desi Nurnaningsih. "Rancangan Aplikasi Pengamanan Data Dengan Algoritma Advanced Encyption Standard (AES)." Jurnal Teknik Informatika 11.2, pp. 177-186, 2018

[6] Sodikin, Luthfia, and Taufik Hidayat. "Analisa Keamanan ECommerce Menggunakan Metode AES Algoritma." Teknokom 3.2 , pp. 8-13, 2020.

[7] Latif, Agustan. "Implementasi Kriptografi Menggunakan Metode Advanced Encryption Standar (AES) Untuk Pengamanan Data Teks." MUSTEK ANIM HA 4.2, pp. 163-172, 2015.

DOI: $\mathrm{xxxx}$

Lisensi: Creative Commons Attribution 4.0 International (CC BY 4.0) 